\title{
Body mass index and all-cause mortality in a large Chinese cohort
}

\author{
Wen-Yuan Lin MD PhD, Shin-Li Tsai MD MS, Jeanine B. Albu MD, Cheng-Chieh Lin MD PhD, Tsai-Chung Li PhD, \\ F. Xavier Pi-Sunyer MD MPH, Pei-Kun Sung MD, Kuo-Chin Huang MD PhD
}

See related commentary by Zhu and colleagues at www.cmaj.ca/cgi/doi/10.1503/cmaj.110142.

\begin{abstract}
Background: Obesity is known to be associated with an increased risk of death, but current definitions of obesity are based on data from white populations. We examined the association between body mass index (BMI) and the risk of death in a large population of adult Chinese people.
\end{abstract}

Methods: We examined the association between body mass index (BMI) and all-cause mortality prospectively among 58738 men and 65718 women aged 20 years and older enrolled in 1998-1999 from four national health screening centres in Taiwan. We used Cox proportional hazards regression analyses to estimate the relative risks of all-cause mortality for different BMI categories during a maximum follow-up of 10 years.

Results: A total of 3947 participants died during the follow-up period. The lowest risk of death was observed among men and women who had a BMI of 24.0-25.9 (mean 24.9). After adjustment for age, smoking status, alcohol intake, betel-nut chewing, level of physical activity, income level and education level, we observed a $\mathrm{U}$-shaped association between $\mathrm{BMI}$ and all-cause mortality. Similar U-shaped associations were observed when we analyzed data by age (20-64 or $\geq 65$ years), smoking (never, $<10$ pack-years or $\geq 10$ pack-years) and presence of a pre-existing chronic disease, and after we excluded deaths that occurred in the first three years of follow-up.

Interpretation: BMI and all-cause mortality had a U-shaped association among adult Chinese people in our study. The lowest risk of death was among adults who had a BMI of 24.0-25.9 (mean 24.9). Our findings do not support the use of a lower cutoff value for overweight and obesity in the adult Chinese population.
$\mathrm{T}$ he prevalence of obesity has dramatically increased in past decades in both developed and developing countries. The World Health Organization (WHO) reported that 1.6 billion adults are overweight and at least 400 million are obese. ${ }^{1}$ The WHO further predicted that by the year 2015, about 2.3 billion adults will be overweight and more than 700 million will be obese. ${ }^{1}$ In Taiwan, according to a national survey performed between 1993-1996 and 2005-2008, the prevalence of overweight and obesity (defined as body mass index $[\mathrm{BMI}] \geq 24 \mathrm{~kg} / \mathrm{m}^{2}$ ) had increased dramatically, from $33.4 \%$ to $50.8 \%$ among men and from $31.7 \%$ to $36.9 \%$ among women. ${ }^{2}$

Overweight and obesity have been recognized as important and independent risk factors for many chronic diseases such as diabetes mellitus, hypertension, stroke, cardiovascular diseases and malignant diseases. ${ }^{3-7}$ Substantial epidemiologic evidence shows that obesity is associated with an increased risk of cardiovascular-related and allcause mortality. ${ }^{8,9}$ Therefore, obesity has become a major public health problem around the world.
Current definitions of obesity and overweight in adults are based on data from white populations. The WHO has proposed another definition for Asian people, but most of the data it used were from cross-sectional studies. ${ }^{10}$ One study showed that, for a given BMI, Asian people had higher body fat than white people. ${ }^{11}$ Furthermore, the association between BMI and all-cause mortality has been reported to be J-shaped or Ushaped. Most of the studies involved white people, with only a few involving Asian populations. $\mathrm{Gu}$ and colleagues reported a U-shaped association between BMI and all-cause mortality among Chinese people. ${ }^{12}$ However, they included only middle-aged adults over 40 years old and not all adults over 20 years.

We designed a large prospective cohort study to assess the association between BMI and allcause mortality in a nationwide representative sample of Chinese adults over 20 years old in Taiwan. We also intended to find the optimal BMI cutoff values for overweight and obesity among Chinese adults.
Competing interests: Jeanine Albu has received consultancy fees and speaker fees from GlaxoSmithKline. She has conducted research supported by grants from Eli Lilly, Hoffmann-

La Roche, Takeda Pharmaceutical, Novo Nordisk and Merck. Xavier Pi-Sunyer served on the advisory board for Novo Nordisk, Orexigen Therapeutics and Vivus; he has received consultancy fees from AstraZeneca. He has conducted research supported by grants from Novo Nordisk, GlaxoSmithKline, Johnson \& Johnson, Takeda Pharmaceutical and Hoffmann-La Roche. No competing interests declared by the other authors.

This article has been peer reviewed.

Correspondence to: Dr. Kuo-Chin Huang, bretthuang@ntu.edu.tw

CMAJ 2011. DOI:10.1503 /cmaj.100303 


\section{Methods}

\section{Study population}

The data were collected from four private national health screening centres in Taiwan from 1998 to 1999 . The registered health practitioners in these centres provide multidisciplinary care to people who are members of these centres. Most of the members undergo a health examination every three to four years, and about $30 \%$ receive the same health check-up every year.

A total of 58738 men and 65718 women aged 20 years and older were recruited. The structure of our study population was similar to the national data for adults published by the Taiwanese government. ${ }^{13}$ Deaths were ascertained by computer linkage to the national death registry using individual identification numbers. All deaths that occurred between study entry and December 2008 were included for analysis.

Approval for patient recruitment and data analyses was obtained from the MJ Research Foundation Review Committee in Taiwan. Informed consent was obtained from every participant.

\section{Anthropometric indices}

Collection of anthropometric data was described in our previous report. ${ }^{14,15}$ In brief, trained staff measured height (to the nearest $0.1 \mathrm{~cm}$ ) and weight (to the nearest $0.1 \mathrm{~kg}$ ) of each participant using an auto-anthropometer (KN-5000A, Nakamura, Tokyo, Japan). Study participants were grouped into nine categories according to their BMI at baseline: $<18.5,18.5-19.9,20.0-21.9$, $22.0-23.9,24.0-25.9,26.0-27.9,28.0-29.9$, $30.0-34.9$, and $\geq 35.0 \mathrm{~kg} / \mathrm{m}^{2}$.

\begin{tabular}{|c|c|c|c|c|c|c|c|c|c|}
\hline \multirow[b]{2}{*}{ Characteristic } & \multicolumn{9}{|c|}{ BMI; \% of participants* } \\
\hline & $\begin{array}{c}<18.5 \\
n=2448\end{array}$ & $\begin{array}{c}18.5-19.9 \\
n=4300\end{array}$ & $\begin{array}{l}20.0-21.9 \\
n=10473\end{array}$ & $\begin{array}{l}22.0-23.9 \\
n=14983\end{array}$ & $\begin{array}{l}24.0-25.9 \\
n=13368\end{array}$ & $\begin{array}{c}26.0-27.9 \\
n=7738\end{array}$ & $\begin{array}{c}28.0-29.9 \\
n=3374\end{array}$ & $\begin{array}{c}30.0-34.9 \\
n=1819\end{array}$ & $\begin{array}{c}\geq 35 \\
n=235\end{array}$ \\
\hline Age, yr, mean (SD) & $39.3(15.6)$ & $39.7(14.8)$ & $41.1(14.5)$ & $43.3(13.8)$ & $44.6(13.4)$ & $45.1(13.3)$ & $44.4(13.4)$ & $41.7(12.9)$ & 37.5 (11.9) \\
\hline Height, cm, mean (SD) & $169.1(6.6)$ & $169.0(6.5)$ & $168.8(6.2)$ & $168.5(6.3)$ & $168.2(6.2)$ & $168.1 \quad(6.1)$ & $168.4(6.3)$ & $169.0(6.4)$ & $170.2(7.1)$ \\
\hline Weight, kg, mean (SD) & $50.3(4.6)$ & $55.3(4.4)$ & $60.1(4.7)$ & $65.4(5.1)$ & $70.4(5.4)$ & $76.1(5.8)$ & $81.9(6.4)$ & $90.3(8.0)$ & $109.0(11.4)$ \\
\hline BMI, mean (SD) & $17.5(0.8)$ & $19.3(0.4)$ & $21.1(0.6)$ & $23.0(0.6)$ & $24.9(0.6)$ & $26.9(0.6)$ & $28.8(0.6)$ & $31.6(1.3)$ & $37.7 \quad(3.9)$ \\
\hline \multicolumn{10}{|l|}{ Smoking status } \\
\hline Current & 46.2 & 43.6 & 40.7 & 38.7 & 39.4 & 40.5 & 42.5 & 44.7 & 56.5 \\
\hline Former & 9.7 & 9.7 & 10.6 & 12.1 & 13.3 & 13.5 & 14.3 & 13.0 & 8.1 \\
\hline Never & 44.1 & 46.7 & 48.7 & 49.2 & 47.3 & 46.0 & 43.2 & 42.3 & 35.4 \\
\hline \multicolumn{10}{|l|}{ Alcohol intake } \\
\hline Current & 24.3 & 25.0 & 27.7 & 30.2 & 33.0 & 33.9 & 34.4 & 35.1 & 22.8 \\
\hline Former & 5.8 & 5.0 & 5.2 & 5.0 & 5.4 & 6.3 & 7.0 & 6.7 & 7.8 \\
\hline Never & 69.9 & 70.0 & 67.1 & 64.8 & 61.6 & 59.8 & 58.6 & 58.2 & 69.4 \\
\hline \multicolumn{10}{|l|}{ Betel-nut chewing } \\
\hline Current & 9.6 & 10.1 & 9.5 & 9.7 & 10.6 & 12.2 & 13.8 & 15.6 & 18.8 \\
\hline Former & 10.9 & 9.5 & 9.3 & 8.5 & 9.8 & 11.0 & 12.6 & 14.8 & 18.4 \\
\hline Never & 79.5 & 80.4 & 81.2 & 81.8 & 79.6 & 76.8 & 73.7 & 69.6 & 62.8 \\
\hline \multicolumn{10}{|l|}{ Level of physical activity } \\
\hline None or mild & 52.1 & 48.6 & 45.5 & 42.6 & 42.8 & 44.7 & 46.4 & 51.0 & 55.6 \\
\hline Moderate & 34.9 & 37.5 & 38.4 & 39.4 & 38.5 & 37.2 & 36.5 & 34.5 & 34.7 \\
\hline Vigorous & 13.1 & 13.8 & 16.1 & 18.0 & 18.7 & 18.1 & 17.1 & 14.5 & 9.7 \\
\hline \multicolumn{10}{|l|}{ Income level } \\
\hline Low & 39.7 & 37.2 & 32.2 & 27.8 & 27.0 & 28.3 & 29.3 & 29.0 & 34.6 \\
\hline Moderate & 55.1 & 57.1 & 59.5 & 61.5 & 60.6 & 59.2 & 58.5 & 60.3 & 55.1 \\
\hline High & 5.2 & 5.7 & 8.3 & 10.7 & 12.4 & 12.5 & 12.2 & 10.7 & 10.3 \\
\hline \multicolumn{10}{|l|}{ Education level } \\
\hline Low & 13.5 & 13.7 & 13.5 & 15.5 & 16.9 & 18.3 & 18.9 & 15.8 & 12.6 \\
\hline Moderate & 38.2 & 36.1 & 34.6 & 33.2 & 34.8 & 36.1 & 37.5 & 39.0 & 41.7 \\
\hline High & 48.3 & 50.2 & 51.8 & 51.3 & 48.4 & 45.6 & 43.6 & 45.2 & 45.7 \\
\hline
\end{tabular}




\section{Other variables}

Smoking status, alcohol intake, betel-nut chewing and level of physical activity were recorded for each participant using a questionnaire. Information about smoking status, alcohol intake and betel-nut chewing at baseline was categorized as "current," "former" or "never."

The cumulative exposure to smoking was assessed by recording the duration (in years) and quantity (in number of cigarettes per day). Former smokers were asked for their age at the time of quitting. To calculate cumulative pack-years of smoking, we multiplied the number of smoking-years by the average number of cigarettes smoked daily and divided the value by 20 . Cumulative pack-years were categorized into two groups: low (<10 pack-years) and high ( $\geq 10$ pack-years).
Physical activity was classified into three levels: none to mild (les than one hour of physical activity per week), moderate (one to four hours per week) and vigorous (five or more hours per week).

Income status was divided into three levels of annual income: low (< US\$12 500), middle (US\$12 500-\$37 500) and high (> US\$37 500).

Education was classified into three levels: low (elementary school and lower), middle (junior and senior high school) and high (college or university and higher).

Participants who reported a history of stroke, cardiovascular disease, cirrhosis of the liver, asthma, chronic renal disease or cancer were defined as having a pre-existing chronic disease $(n=15180)$. The remaining 109276 participants were defined as healthy.

Table 2: Baseline characteristics of women aged 20 years and older in Taiwan, by body mass index (BMI)

\begin{tabular}{|c|c|c|c|c|c|c|c|c|c|}
\hline \multirow[b]{2}{*}{ Characteristic } & \multicolumn{9}{|c|}{ BMI; \% of participants* } \\
\hline & $\begin{array}{c}<18.5 \\
n=6850\end{array}$ & $\begin{array}{c}18.5-19.9 \\
n=10171\end{array}$ & $\begin{array}{c}20.0-21.9 \\
n=16054\end{array}$ & $\begin{array}{l}22.0-23.9 \\
n=13253\end{array}$ & $\begin{array}{l}24.0-25.9 \\
n=9224\end{array}$ & $\begin{array}{l}26.0-27.9 \\
n=5322\end{array}$ & $\begin{array}{l}28.0-29.9 \\
n=2633\end{array}$ & $\begin{array}{l}30.0-34.9 \\
n=1908\end{array}$ & $\begin{array}{c}\geq 35 \\
n=303\end{array}$ \\
\hline Age, yr, mean (SD) & $32.7(10.6)$ & $35.5(11.1)$ & $40.1(12.2)$ & $45.5(13.1)$ & $49.5(12.8)$ & $51.6(12.5)$ & $51.8(12.4)$ & $51.2(13.0)$ & $47.6(13.5)$ \\
\hline Height, cm, mean (SD) & $158.6(5.6)$ & $158.0(5.5)$ & $157.0(5.6)$ & $155.7(5.6)$ & $155.0(5.5)$ & $154.4(5.5)$ & $154.3(5.6)$ & $154.3(5.6)$ & $154.4(6.3)$ \\
\hline Weight, kg, mean (SD) & $44.0(3.7)$ & $48.3(3.5)$ & $51.8(3.8)$ & $55.7(4.1)$ & 59.9 (4.4) & $64.2(4.7)$ & $68.9(5.1)$ & $75.6(6.3)$ & $89.7 \quad(9.5)$ \\
\hline BMI, mean (SD) & $17.5(0.8)$ & $19.3(0.4)$ & $21.0(0.6)$ & $23.0(0.6)$ & $24.9(0.6)$ & $26.9(0.6)$ & $28.9(0.6)$ & 31.7 (1.3) & $37.6(2.4)$ \\
\hline \multicolumn{10}{|l|}{ Smoking status } \\
\hline Current & 9.0 & 7.3 & 5.6 & 4.7 & 3.9 & 4.2 & 4.3 & 5.0 & 6.7 \\
\hline Former & 2.2 & 2.0 & 1.6 & 1.3 & 1.1 & 1.0 & 1.5 & 1.5 & 2.1 \\
\hline Never & 88.8 & 90.7 & 92.8 & 94.0 & 95.0 & 94.8 & 94.2 & 93.5 & 91.2 \\
\hline \multicolumn{10}{|l|}{ Alcohol intake } \\
\hline Current & 5.6 & 4.9 & 5.9 & 5.7 & 5.7 & 5.6 & 4.6 & 5.3 & 6.2 \\
\hline Former & 1.5 & 1.3 & 1.4 & 1.6 & 1.5 & 1.4 & 1.3 & 2.3 & 6.2 \\
\hline Never & 92.9 & 93.8 & 92.7 & 92.8 & 92.8 & 92.9 & 94.1 & 92.4 & 87.6 \\
\hline \multicolumn{10}{|l|}{ Betel-nut chewing } \\
\hline Current & 0.2 & 0.3 & 0.3 & 0.3 & 0.5 & 0.9 & 1.3 & 1.6 & 2.9 \\
\hline Former & 0.2 & 0.1 & 0.2 & 0.4 & 0.3 & 0.5 & 0.5 & 0.9 & 0.4 \\
\hline Never & 99.6 & 99.6 & 99.5 & 99.3 & 99.2 & 98.6 & 98.2 & 98.5 & 96.7 \\
\hline \multicolumn{10}{|l|}{ Level of physical activity } \\
\hline None or mild & 67.2 & 60.2 & 54.7 & 50.2 & 49.0 & 48.9 & 52.7 & 54.6 & 59.2 \\
\hline Moderate & 28.1 & 32.9 & 35.1 & 34.3 & 32.8 & 31.6 & 30.0 & 29.0 & 29.6 \\
\hline Vigorous & 4.7 & 7.0 & 10.2 & 15.5 & 18.2 & 19.5 & 17.2 & 16.5 & 11.2 \\
\hline \multicolumn{10}{|l|}{ Income level } \\
\hline Low & 57.8 & 54.3 & 57.0 & 65.6 & 73.4 & 78.5 & 79.4 & 82.8 & 80.1 \\
\hline Moderate & 39.8 & 42.7 & 39.6 & 31.6 & 24.4 & 19.5 & 17.9 & 15.7 & 18.1 \\
\hline High & 2.4 & 3.0 & 3.4 & 2.8 & 2.2 & 2.1 & 2.7 & 1.5 & 1.8 \\
\hline \multicolumn{10}{|l|}{ Education level } \\
\hline Low & 7.0 & 9.9 & 18.6 & 34.7 & 48.5 & 58.5 & 61.6 & 62.0 & 56.7 \\
\hline Moderate & 38.6 & 39.7 & 40.5 & 37.0 & 32.8 & 28.5 & 26.6 & 26.1 & 28.9 \\
\hline High & 54.4 & 50.5 & 40.9 & 28.3 & 18.7 & 13.0 & 11.8 & 11.9 & 14.4 \\
\hline
\end{tabular}




\section{Statistical analysis}

The data are presented as means with standard deviations for continuous variables. Analysis of variance was used to compare the continuous variables (age, height, weight) across BMI categories. Proportions and categorical variables (e.g., smoking status, alcohol intake and betelnut chewing) were tested with the $\chi^{2}$ test and the two-tailed Fisher exact test when appropriate. We used Cox proportional hazards regression analysis, adjusted for possible confounders, to estimate the relative risk (RR) for all-cause mortality in relation to BMI categories.

We conducted sensitivity analyses to determine the optimal cutoff values of BMI for allcause mortality by dividing BMI values into 14 groups: < 18.5, 18.5-19.9, 20.0-20.9, 21.0-21.9, $22.0-22.9,23.0-23.9,24.0-24.9,25.0-25.9$, 26.0-26.9, 27.0-27.9, 28.0-28.9, 29.0-29.9, $30.0-34.9$ and 35 .

\section{Results}

The baseline characteristics of the study participants by BMI category are shown in Tables 1 and 2. Compared with participants in the highest BMI category ( $\geq 35$ ), those who had a lower BMI were older, more likely to consume alcohol and chew betel nuts, less physically active, in a higher (men) or lower (women) income level, and less educated (women).

During the 10-year follow-up period (1 109273 person-years), 3947 people (2398 men and 1549 women) died. We found a nonlinear association between BMI and the risk of allcause mortality among men and women, even after adjustment for age, smoking status, alcohol intake, betel-nut chewing, level of physical activity, income level and education level (Table 3 , Figure 1). The lowest risk of death was found among men and women with a BMI of 24.0 25.9 (mean 24.9).

There were significant interactions $(p<0.05)$ between BMI categories and certain covariates (age, smoking and pre-existing chronic disease) for predicting the risk of all-cause mortality. As in the primary analysis, we observed significant Ushaped associations between BMI and all-cause mortality when we analyzed data by age (20-64 or $\geq 65$ years), smoking (never, $<10$ pack-years

\begin{tabular}{|c|c|c|c|c|c|}
\hline \multirow[b]{2}{*}{ BMI } & \multirow{2}{*}{$\begin{array}{l}\text { No. of } \\
\text { deaths }\end{array}$} & \multirow{2}{*}{$\begin{array}{c}\text { No. of } \\
\text { person-years }\end{array}$} & \multicolumn{2}{|c|}{ RR $(95 \% \mathrm{Cl})$} & \multirow{2}{*}{$\begin{array}{l}\text { Adjusted RR } \\
\text { for follow-up period } \\
1990-2007 \neq(95 \% \mathrm{Cl})\end{array}$} \\
\hline & & & Crude* & Adjusted $\dagger$ & \\
\hline \multicolumn{6}{|l|}{ Men } \\
\hline$<18.5$ & 145 & 21507 & $1.80(1.50-2.17)$ & $1.65(1.34-2.04)$ & $1.65(1.29-2.10)$ \\
\hline $18.5-19.9$ & 196 & 38092 & $1.47(1.24-1.73)$ & $1.32(1.09-1.60)$ & $1.36(1.10-1.69)$ \\
\hline $20.0-21.9$ & 425 & 92829 & $1.26(1.11-1.44)$ & $1.15(0.99-1.33)$ & $1.10(0.92-1.30)$ \\
\hline $22.0-23.9$ & 586 & 133037 & $1.11(0.98-1.25)$ & $1.14(0.99-1.30)$ & $1.09(0.94-1.27)$ \\
\hline $24.0-25.9$ & 506 & 118723 & 1.00 (ref) & 1.00 (ref) & 1.00 (ref) \\
\hline $26.0-27.9$ & 310 & 68759 & $1.03(0.90-1.19)$ & $1.01(0.86-1.18)$ & $1.00(0.84-1.20)$ \\
\hline $28.0-29.9$ & 148 & 29954 & $1.18(0.98-1.42)$ & $1.12(0.91-1.38)$ & $1.19(0.95-1.50)$ \\
\hline $30.0-34.9$ & 71 & 16083 & $1.40(1.09-1.80)$ & $1.27(0.95-1.70)$ & $1.09(0.76-1.55)$ \\
\hline$\geq 35$ & 11 & 2080 & $2.48(1.36-4.50)$ & $2.37(1.22-4.60)$ & $2.08(0.92-4.67)$ \\
\hline \multicolumn{6}{|l|}{ Women } \\
\hline$<18.5$ & 90 & 61448 & $1.50(1.19-1.90)$ & 1.52 (1.17-1.99) & $1.60(1.19-2.15)$ \\
\hline $18.5-19.9$ & 128 & 91146 & $1.22(0.99-1.50)$ & $1.34(1.06-1.70)$ & $1.22(0.93-1.61)$ \\
\hline $20.0-21.9$ & 265 & 143926 & $1.05(0.89-1.24)$ & $1.18(0.97-1.42)$ & $1.22(0.99-1.51)$ \\
\hline $22.0-23.9$ & 332 & 118733 & $0.99(0.85-1.16)$ & $1.05(0.8-1.26)$ & $1.03(0.84-1.26)$ \\
\hline $24.0-25.9$ & 306 & 82357 & 1.00 (ref) & 1.00 (ref) & 1.00 (ref) \\
\hline $26.0-27.9$ & 202 & 47488 & $1.00(0.84-1.20)$ & $1.03(0.84-1.26)$ & $1.07(0.85-1.34)$ \\
\hline $28.0-29.9$ & 117 & 23422 & $1.16(0.94-1.44)$ & $1.08(0.83-1.39)$ & $1.03(0.77-1.38)$ \\
\hline $30.0-34.9$ & 95 & 16989 & $1.34(1.07-1.69)$ & 1.39 (1.07-1.80) & $1.44(1.08-1.93)$ \\
\hline$\geq 35$ & 14 & 2698 & $1.63(0.96-2.79)$ & $1.65(0.92-2.95)$ & $1.76(0.93-3.34)$ \\
\hline \multicolumn{6}{|c|}{$\begin{array}{l}\text { Note: } \mathrm{Cl}=\text { confidence interval, ref = reference group, } \mathrm{RR}=\text { relative risk. } \\
{ }^{*} \text { Adjusted for age. } \\
\text { †Adjusted for age, smoking status, alcohol intake, betel-nut chewing, level of physical activity, income level and education level. } \\
\text { fOnly deaths that occurred after the first three years of follow-up are included. }\end{array}$} \\
\hline
\end{tabular}


or $\geq 10$ pack-years), and presence or absence of a pre-existing chronic disease (Figure 2).

People 65 years of age and older had a steeper U-shaped curve than the younger participants (Figure 2A). As in the main analysis, the lowest risk of death was observed among people in both age groups who had a BMI of 24.0-25.9. In the highest BMI category, the risk of death was lower among people who had 10 or more cumulative pack-years of smoking than among those who had fewer pack-years or who never smoked (Figure 2B). Among participants with a BMI of less than 24.0, those who had a preexisting chronic disease were at higher risk of death than those without a chronic disease. The reverse was true among those with higher BMIs (Figure 2C).

The U-shaped association between BMI and all-cause mortality remained significant after we excluded participants who died during the first three years of follow-up (Table 3).

In our sensitivity analyses in which we divided BMI values into 14 groups to determine the optimal cutoff values of BMI for all-cause mortality, the lowest risk of death was observed among men with a BMI of 24.0-24.9 (mean 24.5) and among women with a BMI of 25.025.9 (mean BMI 25.5). These findings were consistent with the results of our main analysis (BMI 24.0-25.9) and show the robustness of our results.

\section{Interpretation}

In this population-based prospective study, we found a U-shaped association between BMI and all-cause mortality among adult Chinese people in Taiwan. The risk of death was higher among people with BMIs in the lower and upper categories than among those with BMIs in the middle category. The lowest risk of death was associated with a BMI of 24.0-25.9 (mean 24.9) among both men and women. We observed similar Ushaped associations when we analyzed data by age, smoking and presence of a pre-existing chronic disease, and when we excluded people who died within the first three years of follow-up.

The WHO has proposed lower BMI cutoff

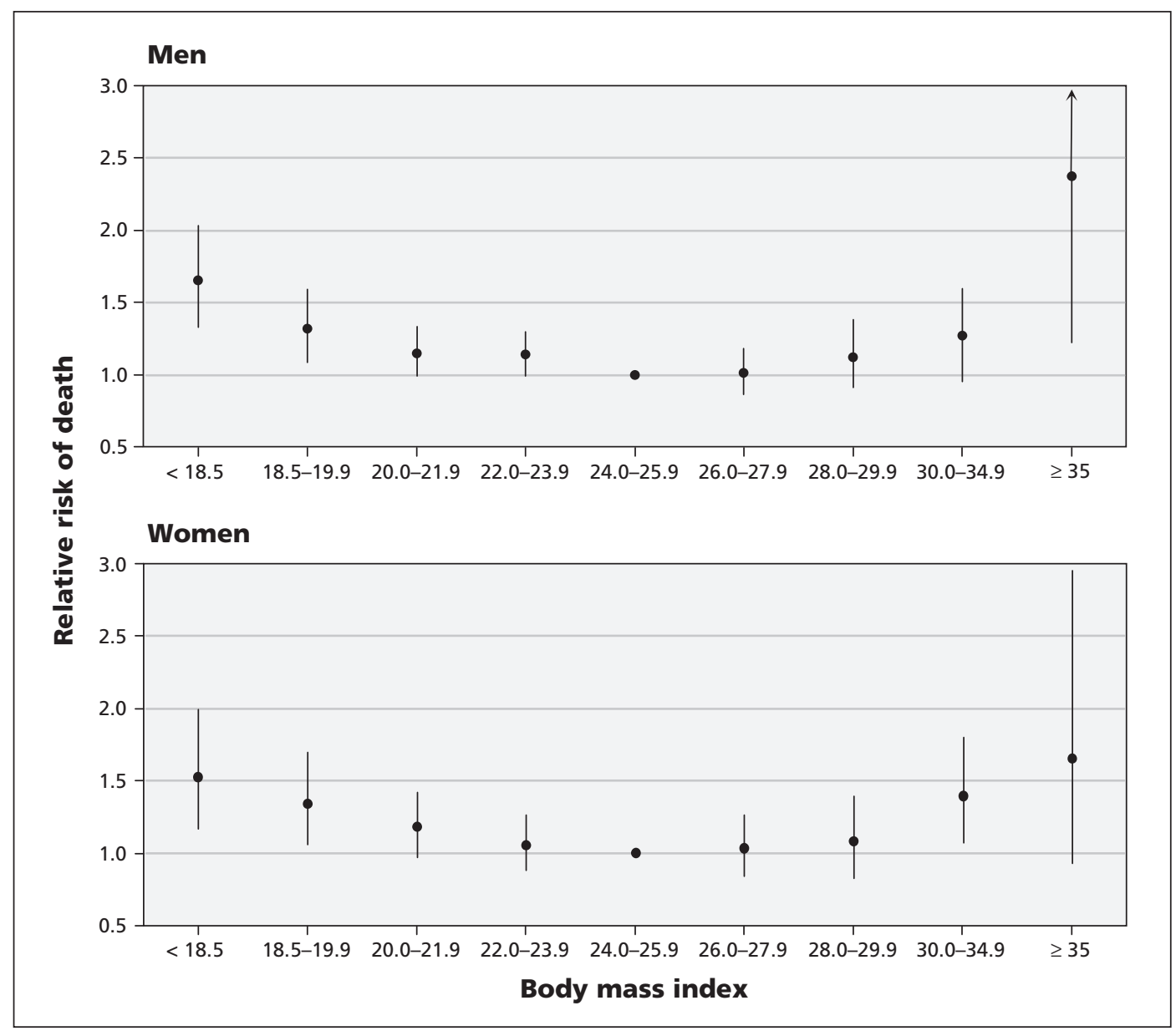

Figure 1: Association between body mass index (BMI) and all-cause mortality among Chinese men and women. Relative risks were adjusted for age, smoking status, alcohol intake, betel-nut chewing, level of physical activity, income level and education level. Error bars indicate $95 \%$ confidence intervals. 
values for defining overweight (23.0-24.9) and obesity $(\geq 25)$ in Asian populations..$^{10}$ However, most of the evidence it used was from crosssectional studies. Earlier prospective studies involving Chinese people reported a U-shaped association between BMI and all-cause mortality and showed that people with a BMI of 24.0-28.0 had the lowest risk of death. ${ }^{12,16,17}$ For example, $\mathrm{Gu}$ and coauthors found that, among 169871 Chinese people aged 40 years and older, both men and women with a BMI of 24.0-24.9 had the lowest risk of death. In white populations, studies have reported a J- or U-shaped association between BMI and all-cause mortality: a
BMI of 23.0-28.0 was associated with the lowest risk of death, with the minimum mortality close to a BMI of 25.0. ${ }^{8,18-20}$

The findings from our primary analysis and sensitivity analyses are consistent with the results of these studies and do not support the use of a lower BMI cutoff value for overweight and obesity in the adult Chinese population.

Previous studies have shown that age is an effect modifier for the association between BMI and risk of death. ${ }^{18,20}$ Weiss and colleagues reported that BMI was inversely related to mortality among elderly people. ${ }^{21}$ In our study, however, the U-shaped association between BMI and

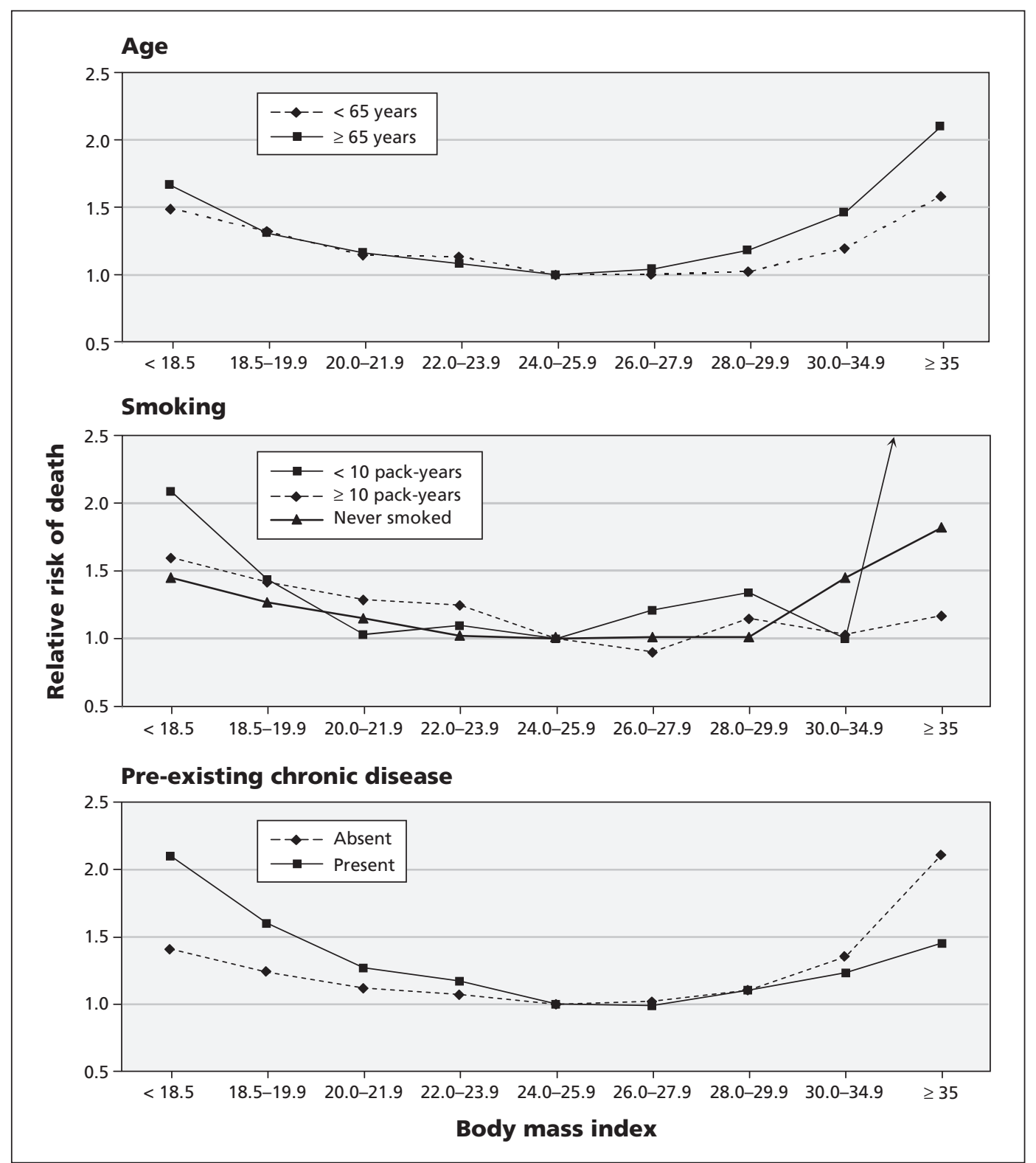

Figure 2: Adjusted relative risks of all-cause mortality by body mass index (BMI) category according to age ( $<65$ or $\geq 65$ years), smoking (never, $<10$ pack-years or $\geq 10$ pack-years) and the presence or absence of pre-existing chronic diseases (stroke, cardiovascular disease, cirrhosis of the liver, chronic renal disease, asthma or cancer). The relative risks were adjusted for age, sex, cumulative pack-years of smoking, alcohol intake, betel-nut chewing, level of physical activity, income level and education level. 
all-cause mortality was significant among participants aged 20-64 years and among those 65 years and older. This finding did not support the theory of "obesity paradox" in elderly people.

Smoking is associated with lower body weight and an increased risk of death. ${ }^{22-24}$ Our findings support the results of previous studies that have shown smokers who have lower BMI values to be at higher risk of death than those who never smoked. ${ }^{12,23}$ We found similar Ushaped associations between BMI and all-cause mortality among participants who never smoked, smokers who had fewer than 10 cumulative pack-years and smokers with 10 or more packyears.

The presence of pre-existing chronic diseases was associated with an increase in all-cause mortality and decreased body weight. We used two criteria to avoid possible bias caused by preexisting chronic disease: we limited the analysis to healthy participants, and we excluded people who died during the first three years of followup. The U-shaped associations between BMI and all-cause mortality remained after making these adjustments. In the lower BMI categories, the risk of death was higher among participants with a pre-existing chronic disease than among healthy participants. This finding confirmed that pre-existing chronic disease was associated with an increased risk of death. In contrast, in the higher BMI categories, the risk of death was lower among participants with a pre-existing chronic disease than among the healthy participants. This finding suggests that obesity may have a protective effect in people with preexisting chronic diseases and is consistent with reports from the United States. ${ }^{25}$

\section{Limitations}

Our study has some limitations worth noting. First, we did not measure weight at the end of the follow-up period. Therefore, we could not determine changes in weight over time or whether there was an association between weight change and mortality. Second, our study population comprised mainly volunteers in generally good health who attended health screening centres. However, the population structure in our study was similar to the national data for adults reported by the Taiwanese government. External validation will be necessary in future studies. Finally, we adjusted for several variables, including smoking status, alcohol intake, betel-nut chewing, level of physical activity, education level and income level, which allowed us to minimize the effect of potential confounders. However, we still could not exclude the possibility of residual confounding.

\section{Conclusion}

Both obesity and underweight were related to an increase in all-cause mortality among adult Chinese people in Taiwan. This U-shaped association remained when we examined data by age ( $<65$ or $\geq 65$ years), smoking (never, $<10$ packyears or $\geq 10$ pack-years) and the presence or absence of pre-existing chronic disease, and when we excluded people who died during the first three years of follow-up. The consistency of our findings with those in other populations supports the argument for a single recommended range of BMI values.

\section{References}

1. World Health Organization. Obesity and overweight [fact sheet 311]. Geneva (Switzerland): The Organization; 2006. Available: www.who.int/mediacentre/factsheets/fs311/en/index.html. (accessed 2010 Dec. 10).

2. Nutrition and health survey in Taiwan 1993-1996 and 20052008. Taipei City (Taiwan): Department of Health; Executive Yuan, R.O.C. (Taiwan); 2009.

3. Calle EE. Obesity and cancer. BMJ 2007;335:1107-8.

4. Obesity: preventing and managing the global epidemic. Report of a WHO consultation. World Health Organ Tech Rep Ser 2000;894:i-xii, 1-253.

5. Narayan KM, Boyle JP, Thompson TJ, et al. Effect of BMI on lifetime risk for diabetes in the U.S. Diabetes Care 2007;30:1562-6.

6. Lin WY, Yang WS, Lee LT, et al. Insulin resistance, obesity, and metabolic syndrome among non-diabetic pre- and post-menopausal women in North Taiwan. Int J Obes (Lond) 2006;30:912-7.

7. Lin WY, Yao CA, Wang HC, et al. Impaired lung function is associated with obesity and metabolic syndrome in adults. Obesity (Silver Spring) 2006;14:1654-61.

8. Pischon T, Boeing H, Hoffmann K, et al. General and abdominal adiposity and risk of death in Europe. $N$ Engl J Med 2008;359: 2105-20.

9. Kannel WB, D'Agostino RB, Cobb JL. Effect of weight on cardiovascular disease. Am J Clin Nutr 1996;63:419S-22S.

10. World Health Organization. The Asia-Pacific perspective: redefining obesity and its treatment. Geneva (Switzerland): The Organization; 2000. Available: www.diabetes.com.au/pdf /obesity_report.pdf (accessed 2010 Dec. 10).

11. Chang $\mathrm{CJ}$, Wu CH, Chang CS, et al. Low body mass index but high percent body fat in Taiwanese subjects: implications of obesity cutoffs. Int J Obes Relat Metab Disord 2003;27:253-9.

12. Gu D, He J, Duan X, et al. Body weight and mortality among men and women in China. JAMA 2006;295:776-83.

13. Statistical Yearbook of Interior 1998-2000. Taipei City (Taiwan): Department of Statistics, Ministry of Interior; Executive Yuan, R.O.C. (Taiwan); 2001. Available: http://sowf.moi.gov.tw /stat/year/elist.htm (accessed 2011 Feb. 17).

14. Lin WY, Chiu TY, Lee LT, et al. Betel nut chewing is associated with increased risk of cardiovascular disease and all-cause mortality in Taiwanese men. Am J Clin Nutr 2008;87:1204-11.

15. Lin WY, Lee LT, Chen CY, et al. Optimal cut-off values for obesity: using simple anthropometric indices to predict cardiovascular risk factors in Taiwan. Int J Obes Relat Metab Disord 2002;26:1232-8

16. Zhou BF. Effect of body mass index on all-cause mortality and incidence of cardiovascular diseases - report for meta-analysis of prospective studies open optimal cut-off points of body mass index in Chinese adults. Biomed Environ Sci 2002;15:245-52.

17. Yuan JM, Ross RK, Gao YT, et al. Body weight and mortality: a prospective evaluation in a cohort of middle-aged men in Shanghai, China. Int J Epidemiol 1998;27:824-32.

18. Flegal KM, Graubard BI, Williamson DF, et al. Excess deaths associated with underweight, overweight, and obesity. JAMA 2005;293:1861-7.

19. Allison DB, Fontaine KR, Manson JE, et al. Annual deaths attributable to obesity in the United States. JAMA 1999;282:1530-8.

20. Calle EE, Thun MJ, Petrelli JM, et al. Body-mass index and mortality in a prospective cohort of U.S. adults. $N$ Engl J Med 1999;341:1097-105.

21. Weiss A, Beloosesky Y, Boaz M, et al. Body mass index is inversely related to mortality in elderly subjects. J Gen Intern Med 2008;23:19-24. 
22. Gu D, Kelly TN, Wu X, et al. Mortality attributable to smoking in China. N Engl J Med 2009;360:150-9.

23. Miyazaki M, Babazono A, Ishii T, et al. Effects of low body mass index and smoking on all-cause mortality among middleaged and elderly Japanese. J Epidemiol 2002;12:40-4.

24. Wilson K, Clark H, Hotz S, et al. Impact of smoking status on weight loss and cardiovascular risk factors. $J$ Epidemiol Community Health 2001;55:213-4.

25. Adams KF, Schatzkin A, Harris TB, et al. Overweight, obesity, and mortality in a large prospective cohort of persons 50 to 71 years old. N Engl J Med 2006;355:763-78.

Affiliations: From the Department of Family Medicine (W.-Y Lin, C.-C. Lin), China Medical University Hospital, Taichung, Taiwan; the School of Medicine (W.-Y. Lin, C.-C. Lin), the Graduate Institute of Clinical Medical Science (W.-Y. Lin, Huang) and the Graduate Institute of Biostatistics (Li), China Medical University, Taichung, Taiwan; the Department of Family Medicine (Tsai, Huang), National Taiwan University Hospital, Taipei, Taiwan; the Institute of Health Care Administration (C.-C. Lin, Li), College of Health Science, Asia University, Taichung, Taiwan; the MJ Health Screening Center (Sung), Taipei, Taiwan; and the New York Obesity Research Center (Albu, Pi-Sunyer), St. Luke's-Roosevelt Hospital, Columbia University, New York, NY

Contributors: Wen-Yuan Lin and Kuo-Chin Huang had full access to all of the data and take responsibility for the integrity of the data and the accuracy of the data analysis. Wen-Yuan Lin, Cheng-Chieh Lin and Kuo-Chin Huang were involved in the study concept and design. Jeanine Albu, Cheng-Chieh Lin, Xavier Pi-Sunyer and Kuo-Chin Huang supervised the study. Shin-Li Tsai, Tsai-Chung Li and Pei-Kun Sung acquired the data. Wen-Yuan Lin, Jeanine Albu, Tsai-Chung Li and Xavier Pi-Sunyer were involved in the analysis and interpretation of data. WenYuan Lin, Shin-Li Tsai and Tsai-Chung Li performed the statistical analysis. Wen-Yuan Lin and Kuo-Chin Huang drafted the manuscript. Jeanine Albu, Cheng-Chieh Lin, Tsai-Chung Li, Xavier Pi-Sunyer and Kuo-Chin Huang critically revised the manuscript for important intellectual content. Wen-Yuan Lin, Cheng-Chieh Lin, Tsai-Chung Li and Xavier Pi-Sunyer obtained funding. Cheng-Chieh Lin and Pei-Kun Sung provided administrative, technical and material support. All of the authors approved the final version of the manuscript submitted for publication.

Funding: This study was supported by grants from the China Medical University Hospital (grant nos. DMR-97-149, DMR-98-090 and DMR-99-110), the Taiwan Department of Health Clinical Trial and Research Center of Excellence (grant no. DOH99-TD-B-111-004) and the US National Institutes of Health (grant no. DK 026687).

Acknowledgement: The authors thank staff from the MJ Health Screening Center for assistance with data collection. 